V.

\title{
A Case of Adeno-Myoma Uteri.
}

\author{
By C. E. I'ursLow, M.D. (Lond.), M.R.C.P. (Lond.), \\ Honorary Obstetric Offcer, Queen's Hospital, Birmingham.
}

THE patient, a married nullipara of 34 , was admitted to hospital under my care on April 15, 1909.

History. Menstruation had been profuse and painful for some years, for the past fire years she had had pain in the right iliac region, severe at times, and always bad after exertion, rendering her to some extent an invalid.

Condition on admission. On abdominal examination a very hard, irregular swelling could be felt above the pubes, lying mainly on the right of the median line; bimanual examination showed this to be the uterus, and the diagnosis of multiple fibroids was made.

Operation. The patient was placed in the Trendelenberg position and abdominal supra-vaginal hysterectomy performed. The largest fibroid, the size of an orange, deeply invaded the right broad ligament and had to be enucleated therefrom.

The peritoneum of the broad ligaments was united with a continuous fine silk suture, and the abdominal wall closed in layers. The patient made an uninterrupted recovery and left the hospital looking much better and feeling stronger than on admission.

Description of specimen. To the naked eye this appeared to be a typical example of multiple fibroids of the uterus; the separate tumours were cut across with a knife and all had an unusually firm, white, appearance, with the exception of one of the smaller superitoneal growths; in the centre of this was a softened area, about $\frac{3}{4} \mathrm{in}$. in diameter, surrounded by firm white tissue, the area itself having a much darker appearance; sections of this were taken and, under the microscope, the softened area showed typical adenomatous tissue, viz.: numerous gland spaces, lined by a single layer of columnar epithelium and having a cellular inter-alveolar stroma. This adenomatous tissue was sharply defined and did not spread into the surrounding mass, which had the typical structure of an ordinary fibro-myoma.

In an abstract of a paper by Grunbaum (the former appearing in this Journal, vol. xiv, No. 2, p. 126) "On sixteen cases of Adenomyoma," it is stated that, in four, multiple fibroids were present, and 
the conclusion is arrived at that adeno-myoma, itself, has no specific syndrome; none of the cases recorded were diagnosed before operation.

My case appears to differ from most of those recorded in that the adenomatous tissue was localised and not diffused throughout the uterine wall, as is usual, so that its origin by direct spreading from the endometrium is not capable of proof, and the growth resembles closely the tumours described by von Recklinghausen, the origin of which was attributed by him to Wolffian "rest cells"; it also further agrees with these in that it was situated near the uterine cornu and on the dorsal aspect of the uterus.

Cameron and Taylor, in this JourNaL, vol. v, p. 251, would deny the right of the tumour $I$ have described to the title of adeno-myoma, and prefer to designate it "myoma with glandular inclusions," reserving the name adeno-myoma for the diffuse form.

I am indebted to Dr. Leonard Mackey, pathologist to the hospital, for the sections and photomicrographs and to Dr. A. A. Saunders, obstetric house-surgeon, for assistance with the case. 